\title{
Editorial
}

\section{0th Meeting of the French Microscopy Society - Grenoble 2007}

The Meeting of the French Microscopy Society $(\mathrm{Sf} \mu)$ convenes every two years to gather the French microscopist community around oral and poster presentations, as well as two day pre-congress workshops and a technical exhibition of microscopes and attachments. It is an opportunity to take stock of the scientific and technological advances made in microscopy and its application to physics, materials science, biology, chemistry, and earth sciences, among countless other fields.

This 10th edition of the Sf $\mu$ meeting was organised in Grenoble, from June 5th to 8th, 2007, alongside the Groupement National de Microscopie Électronique à Balayage (GN-MEBA) and the Cercle Français de Pathologie Ultrastructurale (CFPU).

The Scientific Programme Committee, taking advantage of Grenoble's global reputation in electron microscopy and synchrotron radiation, put special emphasis on three different types of microscopy - electron, photon (visible) and X-ray - to highlight both their complementarities and their specificities, with the goal of attracting the widest audience of microscopists and to encourage synergies.

The three talks of the opening session were given by renowned leaders in these three fields: Jany Thibault (CNRS/Marseille), Cristoph Cremer (Kirchhoff Institute for Physics/Heidelberg) and Jean Susini (ESRF/Grenoble). The scientific programme was equally organised around three main thrusts: (1) advances in electron, photon and X-ray microscopy; (2) 3-D microscopy; and (3) measurement of orientation texture, stress and strains. These subjects were the topics of plenary sessions, accompanying sixteen symposiums devoted in particular to the "Physics-Materials Science" and "Biology-Soft Matter" communities. Among these symposiums, several were related to the specific activities of the Grenoble microscopist community: "Nano objects, nano particles, organic or hybrid colloids", "Auto-assembly, Autoorganisation and Liquid Crystals", "Functional Materials for Microelectronics, Magnetism and Optics", "Viruses", and "Materials for Energy and Transportation".

Altogether, some 450 researchers and engineers from physics, materials science, chemistry, soft matter, geology, biology, and medicine, coming from both academia and industry, met during these four days in symposia on the development and application of microscopy. Five select papers from these symposia are published in full on the following pages of this issue of EPJAP, and the complete list of abstracts for presented papers may be downloaded from http://sfmu2007.free.fr/files/Actes_sfmu2007.pdf.

Philippe Buffat, Vice-President $\mathrm{Sf} \mu$
Marie Cheynet

President of the Organisation Committee

Sf $\mu$ Grenoble 2007 